\title{
Timing van de PSMA PET/CT-scan bij biochemisch recidief na radicale prostatectomie
}

\author{
Henk B. Luiting · Pim J. van Leeuwen - Sebastiaan Remmers · Maarten Donswijk - Martijn B. Busstra · \\ Ingrid L. Bakker · Tessa Brabander · Marcel Stokkel · Henk G. van der Poel · Monique J. Roobol
}

Published online: 15 September 2020

(C) The Author(s) 2020

Samenvatting We presenteren hier een model dat de kans op het detecteren van een prostaatkankerrecidief buiten de prostaatfossa op de prostaatspecifiek membraanantigeen (PSMA) positronemissietomografie/computertomografie (PET/CT)-scan voorspelt bij patiënten met een biochemisch recidief (BCR) na radicale prostatectomie (RP). 419 patiënten met een BCR prostaatspecifiek antigeen (PSA) $<2,0 \mathrm{ng} / \mathrm{ml}$ ) na RP zonder hormoontherapie die een ${ }^{68} \mathrm{Ga}$-PSMA PET/CT-scan ondergingen, werden geïncludeerd. Met multivariabele logistische regressieanalyse werden voorspellers voor de detectie van prostaatkankerrecidief buiten de prostaatfossa geïdentificeerd. Bij een mediane PSA-waarde van $0,40 \mathrm{ng} / \mathrm{ml}$ (interkwartielafstand 0,30-0,70) werd met PSMA PET/CT bij 174 (42\%) patiënten een pros-

Dit artikel is een vertaling van het manuscript dat resulteerde in de volgende publicatie in Journal of Urology: Luiting HB, van Leeuwen PJ, Remmers S, Donswijk M, Busstra MB, Bakker IL, et al. The optimal timing for PSMA PET/CT in patients with biochemical recurrence after radical prostatectomy. J Urol. 2020 Mar 9;101097JU0000000000001012. Epub ahead of print. https://doi.org/10.1097/JU.0000000000001012.

drs. H. B. Luiting ( $₫)$ · drs. S. Remmers · drs. M. B. Busstra · drs. I. L. Bakker · prof. dr. M. J. Roobol

afdeling Urologie, Erasmus MC, Rotterdam, Nederland h.luiting@erasmusmc.nl

dr. P. J. van Leeuwen · dr. H. G. van der Poel afdeling Urologie, Nederlands Kankerinstituut, Amsterdam, Nederland

drs. M. Donswijk · dr. M. Stokkel

afdeling Nucleaire Geneeskunde, Nederlands

Kankerinstituut, Amsterdam, Nederland

\section{dr. T. Brabander}

afdeling Radiologie \& Nucleaire Geneeskunde, Erasmus MC, Rotterdam, Nederland taatkankerrecidief buiten de prostaatfossa gedetecteerd. Significante voorspellers voor het detecteren van prostaatkankerrecidief buiten de prostaatfossa waren de PSA-waarde ten tijde van de PSMA PET/CTscan en de Gleason-score, het lymfeklierstadium en het snijrandstadium van het RP-preparaat. De PSAwaarde ten tijde van de PSMA PET/CT en de Gleasonscore, het lymfeklierstadium en het snijrandstadium van het RP-preparaat waren belangrijke voorspellers voor het vinden van prostaatkankerrecidief buiten de prostaatfossa met de PSMA PET/CT. Het dashboard (https://psma.prostatecancer-riskcalculator. com/) kan gebruikt worden om het klinisch meest relevante moment voor het verrichten van een PSMA PET/CT-scan te bepalen.

Trefwoorden predictiemodel - riskcalculator . biochemisch prostaatkankerrecidief · prostaatfossa

The optimal timing for PSMA PET/CT in patients with biochemical recurrence after radical prostatectomy

Abstract We created a model predicting the probability to detect prostate cancer recurrence outside the prostatic fossa in men with biochemical recurrence (BCR) after radical prostatectomy (RP). 419 patients with BCR (prostate specific antigen [PSA] $<2.0 \mathrm{ng} / \mathrm{ml}$ ) after RP without hormone therapy underwent a ${ }^{68} \mathrm{Ga}$-Prostate Specific Membrane Antigen (PSMA) Positron Emission Tomography/Computer Tomograpy (PET/CT)-scan. Predictors for the detection of prostate cancer recurrence outside the prostatic fossa were identified using multivariable logistic regression analysis. At a median PSA of $0,40 \mathrm{ng} / \mathrm{ml}$ (interquartile range $0,30-0,70$ ), PSMA PET/CT detected prostate cancer recurrence outside the prostatic fossa in $174(42 \%)$ patients. Significant predictors for the de- 
tection of prostate cancer recurrence outside the prostatic fossa were PSA value at time of scanning and RP specimen characteristics Gleason-score, lymph node status and surgical margin status. PSA value at time of scanning and RP specimen characteristics, Gleasonscore, lymph node status and surgical margin status are all important predictors for the probability to detect prostate cancer recurrence outside the prostatic fossa. The dashboard (https://psma.prostatecancerriskcalculator.com/) can be used to determine the clinical most optimal moment to perform a PSMA PET/CT scan.

Keywords prediction model $\cdot$ riskcalculator . biochemical prostate cancer recurrence $\cdot$ prostatic fossa

\section{Introductie}

Een radicale prostatectomie is een curatieve behandeling voor patiënten met een gelokaliseerd prostaatcarcinoom. De kankerspecifieke overleving na een radicale prostatectomie is goed, maar bij circa $30-50 \%$ van de patiënten keert de ziekte terug [1-3]. Prostaatkankerrecidief wordt gedetecteerd door het meetbaar worden van het prostaatspecifiek antigen (PSA) en dit wordt een biochemisch recidief genoemd. Patiënten met een biochemisch recidief kunnen in aanmerking komen voor aanvullende behandelingen waarbij nabestraling op de prostaatfossa de curatieve behandeloptie is. Het nabestralen van de prostaatfossa is het meest effectief bij lage PSA-waarden [4, 5]. Indien de prostaatkanker terugkeert buiten de prostaatfossa is het nabestralen van de prostaatfossa niet effectief. De prostaatspecifiek membraanantigeen (PSMA) positronemissietomografie/computertomografie (PET/CT) is de beste methode om prostaatkankerrecidief te detecteren bij lage PSA-waarden. Om deze reden adviseren de richtlijnen van zowel de NVU als de EAU een PSMA PET/CT-scan te maken bij patiënten met een biochemisch recidief na radicale prostatectomie vanaf een PSA-waarde van $0,2 \mathrm{ng} / \mathrm{ml}[6,7]$. Een andere voorwaarde voor het maken van zo'n scan is dat de uitkomst van de scan invloed moet kunnen hebben op het vervolgbeleid.

De detectie van prostaatkankerrecidief buiten de prostaatfossa kan falende nabestraling op de prostaatfossa en de daarbij horende bijwerkingen voorkomen. Bovendien kan er bij de detectie van oligometastatische ziekte gekozen worden voor een metastasegerichte therapie. De detectie van prostaatkankerrecidief buiten de prostaatfossa heeft daarmee dus invloed op het vervolgbeleid. We hebben de invloed van verschillende klinische variabelen op de kans dat een prostaatkankerrecidief buiten de prostaatfossa wordt gedetecteerd door de PSMA PET/CT-scan onderzocht en verwerkt tot een voorspellend model. Daarnaast hebben we een multinomiale logistische regressieanalyse uitgevoerd om te bepalen of klinische variabe- len konden voorspellen of de prostaatkanker gerecidiveerd was binnen of buiten de bekkenregio.

\section{Materiaal en methode}

\section{Patiëntenpopulatie}

Het onderzoek werd uitgevoerd in een samenwerking tussen het Erasmus MC en het Antoni van Leeuwenhoek (AvL). Alle patiënten met een biochemisch recidief na radicale prostatectomie die een PSMA PET/CT-scan ondergingen, werden retrospectief geïncludeerd. Patiënten met een PSA-waarde $>2 \mathrm{ng} / \mathrm{ml}$ en patiënten die hormoontherapie ontvingen na de radicale prostatectomie werden geëxcludeerd. Patiëntgegevens, pathologische variabelen, PSA-waarden en de PSMA PET/CT-uitslag werden verkregen uit het elektronisch patiëntendossier.

\section{Scanprotocol}

In beide centra werd ${ }^{68}$ Ga-PSMA-11 als tracer gebruikt. De tracer werd toegediend als bolusinjectie (1,5 MBq/kg in het Erasmus MC/100MBq fixed-dose in het AvL). Patiënten kregen $20 \mathrm{mg}$ furosemide voorafgaand aan de toediening van de tracer.

De scangegevens van het Erasmus MC zijn: Siemens Biograph mCT, dosisgemoduleerde low dose CT-scan (30 ref mAs, $3 \mathrm{~mm}$ reconstructie) van proximale femur tot de schelbasis, gevolgd door PETbeeldvorming van dezelfde regio. Patiënten met een gewicht onder de $70 \mathrm{~kg}$ werden 3 minuten per bedpositie gescand en patiënten boven de $70 \mathrm{~kg} 4$ minuten per bedpositie.

De scangegevens van het AvL zijn: Philips Gemini TF-II PET/16 slice CT, dosisgemoduleerde low dose CT-scan (40 mAs, $2 \mathrm{~mm}$ reconstructie) van proximale femur tot de schelbasis, gevolgd door PET-beeldvorming van dezelfde regio: 3 minuten per bedpositie voor de pelvis/abdomen en 2 minuten voor de rest van het lichaam.

Alle PSMA PET/CT-scans werden beoordeeld door ervaren nucleair geneeskundigen. In het Erasmus MC gebruikte bij het scoren een vijfpuntsschaal ('zeker negatief', 'waarschijnlijk negatief', 'onduidelijk', 'waarschijnlijk positief', 'zeker positief'). 'Waarschijnlijk positief' en 'zeker positief' werden als positief gescoord. In het AvL werd op een tweepuntsschaal gescoord ('negatief' of 'positief'). Bij onduidelijke PSMA PET/CT-scans werd het eindoordeel van het multidisciplinair onderzoek als definitief positief of negatief genomen.

\section{Statistische analyse}

We gebruikten multivariabele logistische regressie om voorspellers voor de detectie van prostaatkankerrecidief buiten de prostaatfossa door middel van de PSMA $\mathrm{PET} / \mathrm{CT}$-scan mee te identificeren. In de regressieana- 


\section{Artikel}

Tabel 1 Patiëntkarakteristieken

Tabel 2 De odds ratio's voor het detecteren van prostaatkanker buiten de prostaatfossa op de ${ }^{68} \mathrm{Ga}$ PSMA PET/CT-scan voor de klinische variabelen en de gecorrigeerde odds ratio's die gebruikt zijn bij het creëren van het dashboard

\begin{tabular}{|c|c|c|c|c|c|}
\hline \multirow[b]{2}{*}{ aantal patiënten (\%) } & \multicolumn{2}{|c|}{$\begin{array}{l}\text { geen uitzaaiingen } \\
\text { op de PSMA PET/CT-scan }\end{array}$} & \multicolumn{2}{|c|}{$\begin{array}{l}\text { wel uitzaaiingen } \\
\text { op de PSMA PET/CT-scan }\end{array}$} & \multirow[t]{2}{*}{$p$-waard } \\
\hline & 245 & $(58 \%)$ & 174 & $(42 \%)$ & \\
\hline PSA: mediaan (IQR) ng/ml & \multicolumn{2}{|c|}{$0,40(0,25-0,50)$} & \multicolumn{2}{|c|}{$0,53(0,35-0,90)$} & $<0,001$ \\
\hline \multicolumn{5}{|l|}{$\mathrm{pGG}, n,(\%)$} & \multirow[t]{7}{*}{$<0,001$} \\
\hline 1 & 37 & (15) & 14 & (8) & \\
\hline 2 & 95 & (39) & 46 & (27) & \\
\hline 3 & 63 & (26) & 50 & (29) & \\
\hline 4 & 35 & (14) & 27 & 16) & \\
\hline 5 & 14 & (6) & 35 & (20) & \\
\hline $\mathrm{nb}$ & 1 & & 2 & & \\
\hline \multicolumn{5}{|l|}{ pT-stadium, $n,(\%)$} & \multirow[t]{5}{*}{0,008} \\
\hline pT2 & 113 & (46) & 54 & (31) & \\
\hline рT3a & 61 & (25) & 51 & (30) & \\
\hline pT3b & 70 & (29) & 67 & (39) & \\
\hline $\mathrm{nb}$ & 1 & & 2 & & \\
\hline \multicolumn{5}{|l|}{$\mathrm{pN}$-stadium $n,(\%)$} & \multirow[t]{5}{*}{0,004} \\
\hline $\mathrm{pNx}$ & 143 & (58) & 80 & (47) & \\
\hline pNO & 64 & (26) & 43 & (25) & \\
\hline pN1 & 38 & (16) & 49 & (28) & \\
\hline $\mathrm{nb}$ & 0 & & 2 & & \\
\hline positieve snijrand & 111 & (45) & 64 & (37) & 0,10 \\
\hline nabestraling ${ }^{b}$ & 47 & (19) & 54 & (31) & 0,007 \\
\hline \multicolumn{6}{|c|}{$\begin{array}{l}\text { IQR interkwartielafstand, } p G G \text { pathologische grade group, } n b \text { niet beschikbaar, } P S M A \text { prostaatspecific membraanantigen, } \\
\text { PET/CT positronemissietomografie/computertomografie, PSA prostaatspecifiek antigeen, } p T \text {-stadium pathologisch } \\
\text { T-stadium, } p N \text {-stadium pathologisch N-stadium } \\
\text { aPSA ten tijde van de PSMA PET/CT-scan } \\
\text { 'Op het prostaatbed voorafgaand aan de PSMA PET/CT-scan }\end{array}$} \\
\hline
\end{tabular}

\begin{tabular}{|c|c|c|c|}
\hline variabele & odds ratio (95\%-BI) & shrinkage corrected odds ratio & $p$-waarde \\
\hline $\log _{2} P S A^{a}$ & $2,02(1,56-2,66)$ & 1,85 & $<0,001$ \\
\hline \multicolumn{4}{|l|}{$\mathrm{pGG}$} \\
\hline \multicolumn{4}{|l|}{ pGG1 } \\
\hline pGG2 & $1,49(0,68-3,38)$ & 1,41 & 0,3 \\
\hline pGG3 & $2,60(1,15-6,13)$ & 2,31 & 0,024 \\
\hline pGG4 & $2,06(0,82-5,30)$ & 1,88 & 0,13 \\
\hline pGG5 & $8,15(3,00-23,50)$ & 6,26 & $<0,001$ \\
\hline \multicolumn{4}{|c|}{ pT-stadium } \\
\hline \multicolumn{4}{|l|}{$\mathrm{T} 2$} \\
\hline Т3a & $1,33(0,74-2,36)$ & 1,28 & 0,3 \\
\hline T3b & $1,08(0,60-1,94)$ & 1,07 & 0,8 \\
\hline \multicolumn{4}{|c|}{ pN-stadium } \\
\hline \multicolumn{4}{|l|}{ pNO } \\
\hline $\mathrm{pNx}$ & $1,71(0,99-2,98)$ & 1,60 & 0,056 \\
\hline pN1 & $2,42(1,33-4,45)$ & 2,16 & 0,004 \\
\hline \multicolumn{4}{|c|}{ positieve snijrand } \\
\hline \multicolumn{4}{|l|}{ nee } \\
\hline ja & $0,56(0,35-0,88)$ & 0,60 & 0,014 \\
\hline \multicolumn{4}{|c|}{ nabestraling op het prostaatbed } \\
\hline \multicolumn{4}{|l|}{ nee } \\
\hline ja & $1,40(0,83-2,37)$ & 1,34 & 0,21 \\
\hline
\end{tabular}




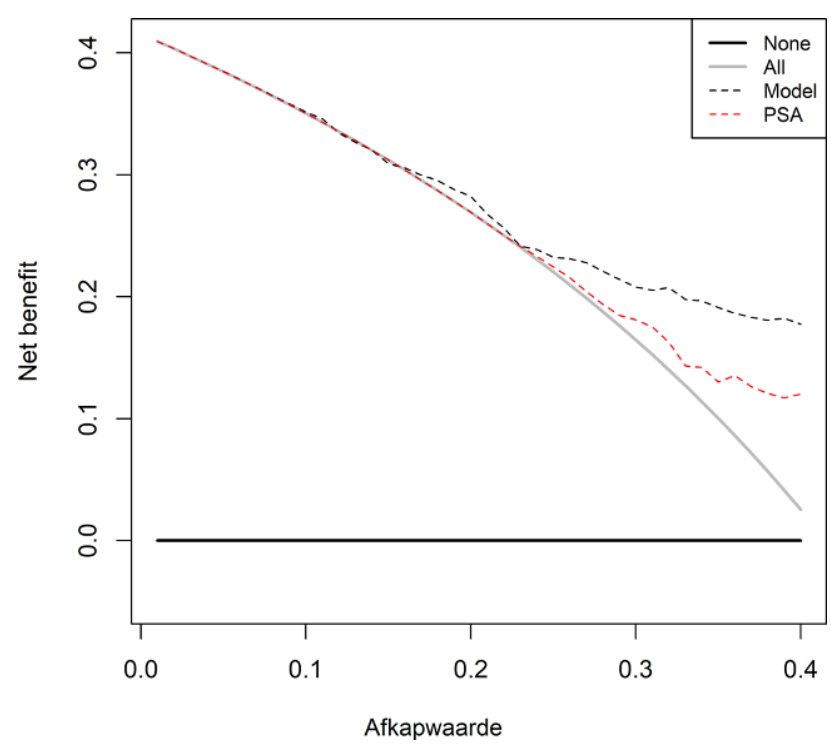

Figuur 1 De decision curve analysis die de netto benefit van het model afbeeldt voor het voorspellen van uitzaaiingen op de ${ }^{68} \mathrm{Ga}-\mathrm{PSMA}$ PET/CT-scan

lyse includeerden we de volgende variabelen: (a) pathologische T-stadium (pT-stadium), (b) pathologische grade group (pGG), (c) snijrandstadium (negatief vs. positief), (d) pathologisch lymfeklierstadium ( $\mathrm{pN}$ stadium), (e) nabestraling voor de PSMA PET/CT-scan ('niet' vs. 'wel') en (f) de binaire logaritmische transformatie van de PSA-waarde ten tijde van de PSMA PET/CT-scan. Daarnaast hebben we een multinomiale logistische regressie uitgevoerd om te bepalen of deze variabelen konden voorspellen of de prostaatkanker teruggekeerd was binnen of buiten de bekkenregio.

Om te bepalen of de categorische variabelen het model verbeterden, gingen we na of het model mét de categorische variabele beter op de data paste dan een model zonder deze categorische variabelen. Om het overfitten (met andere woorden, het model past te nauw op onze dataset en voorspelt dan mogelijk niet betrouwbaar toekomstige observaties) te minimaliseren, hebben we de schatting van onze parameters aangepast met een krimpingsfactor, die werd verkregen uit 200 gebootstrapte steekproeven [8, 9]. Het discriminerend vermogen van het model hebben we verkregen met het oppervlakte onder de receiver operating curve (area under the receiver operating curve; AUC) met 2000 gebootstrapte steekproeven. De klinische meerwaarde van het gecorrigeerde model hebben we bepaald met behulp van analyse van de beslissingscurve (beter bekend als de decision curve analysis; DCA). Ontbrekende data van variabelen werden vijf keer geïmputeerd met matching op basis van voorspeld gemiddelde. Alle statistische analyses werden gedaan met $\mathrm{R}$ versie 3.5.1.

\section{Resultaten}

Tabel 1 toont de patiëntkarakteristieken van de 419 geïncludeerde patiënten. De mediane PSA-waarde ten tijde van de PSMA PET/CT-scan was 0,40 (interkwartielafstand (IQR) 0,30-0,70) ng/ml. De PSMA PET/CT detecteerde prostaatkanker in de pelviene lymfeklieren ( \pm de prostaatfossa) bij 118 (28\%) patiënten, buiten het bekkengebied ( \pm de pelviene lymfeklieren en/of de prostaatfossa) bij 56 (13\%) patiënten en 35 (8\%) patiënten hadden alleen een lokaal recidief.

De multivariabele logistische regressieanalyse liet zien dat de PSA-waarde ten tijde van de PSMA PET/CT-scan en de grade group, het lymfeklierstadium en het snijrandstadium van het radicale prostatectomiepreparaat significante voorspellers zijn voor het detecteren van prostaatkankerrecidief buiten de prostaatfossa op de PSMA PET/CT-scan (tab. 2). Ter illustratie, een patiënt met een biochemisch recidief na een radicale prostatectomie bij wie op de scan een pGG5-tumor te zien was, heeft 8,2 keer zoveel kans om gedetecteerd te worden met een prostaatkankerrecidief buiten de prostaatfossa op de PSMA PET/CTscan als een patiënt met een pGG1-tumor bij dezelfde PSA-waarde. De categorische variabele pGG verbetert de fit van het model $\chi^{2}(4)=24,1(p<0,001)$, net als het pN-stadium $\chi^{2}(2)=10,1 \quad(p=0,006)$. Dit toont aan dat zowel pGG als pN-stadium significante voorspellers zijn voor het detecteren van prostaatkankerrecidief buiten de prostaatfossa met PSMA PET/CT.

De mediane gebootstrapte AUC was 0,75 (IQR 0,73-0,77). Analyse van de beslissingscurve toont een klinisch voordeel van het model vanaf een kans van 0,16 in vergelijking met een model waarin iedereen een PSMA PET/CT-scan zou krijgen (fig. 1). Om het gebruiksgemak voor clinici te verhogen, is het model in een dashboard verwerkt (https://psma. prostatecancer-riskcalculator.com/). Figuur 2 illustreert het gebruik van het dashboard.

In tab. 3 is het percentage PSMA PET/CT-scan genoteerd dat niet gemaakt zou worden bij verschillende afkapwaarden van het model en daarbij hoeveel van deze PSMA PET/CT-scans een prostaatkankerrecidief buiten de prostaatfossa detecteerde. Een afkapwaarde van $20 \%$ leidt tot een afname van het aantal PSMA PET/CT-scans met $16 \%$ ( $n=67)$, waarvan er negen een prostaatkankerrecidief buiten de prostaatfossa detecteerde. In het multinomiaal logistische model werden geen significante variabelen gevonden die voorspellen of prostaatkanker terugkeert binnen of buiten het bekken (tab. 4).

\section{Discussie}

De richtlijnen van de NVU en de EAU adviseren een PSMA PET/CT-scan te maken bij patiënten met een biochemisch recidief na radicale prostatectomie vanaf een PSA-waarde van $0,2 \mathrm{ng} / \mathrm{ml}$, indien de uitkomst van de PSMA PET/CT de vervolgbehandeling zou kunnen 
Figuur 2 Het dashboard dat de kans aangeeft op het vinden van prostaatkanker buiten de prostaatfossa bij twee virtuele patiënten met dezelfde PSA-waarde ten tijde van de scan. Patiënt $A$ had een pT3aGG5pN1R0-tumor en heeft een kans op het vinden van een uitzaaiing van $69 \%$ bij een PSAwaarde van $0,2 \mathrm{ng} / \mathrm{ml}$ ten tijde van de PSMA PET/CTscan. Patiënt $B$ had een pT2GG1pN0R1-tumor en heeft bij dezelfde PSAwaarde een kans van $7 \%$. Deze twee virtuele patiënten laten het belang zien van de verschillende klinische variabelen bij het bepalen van het optimale moment voor het maken van een PSMA PET/CT-scan
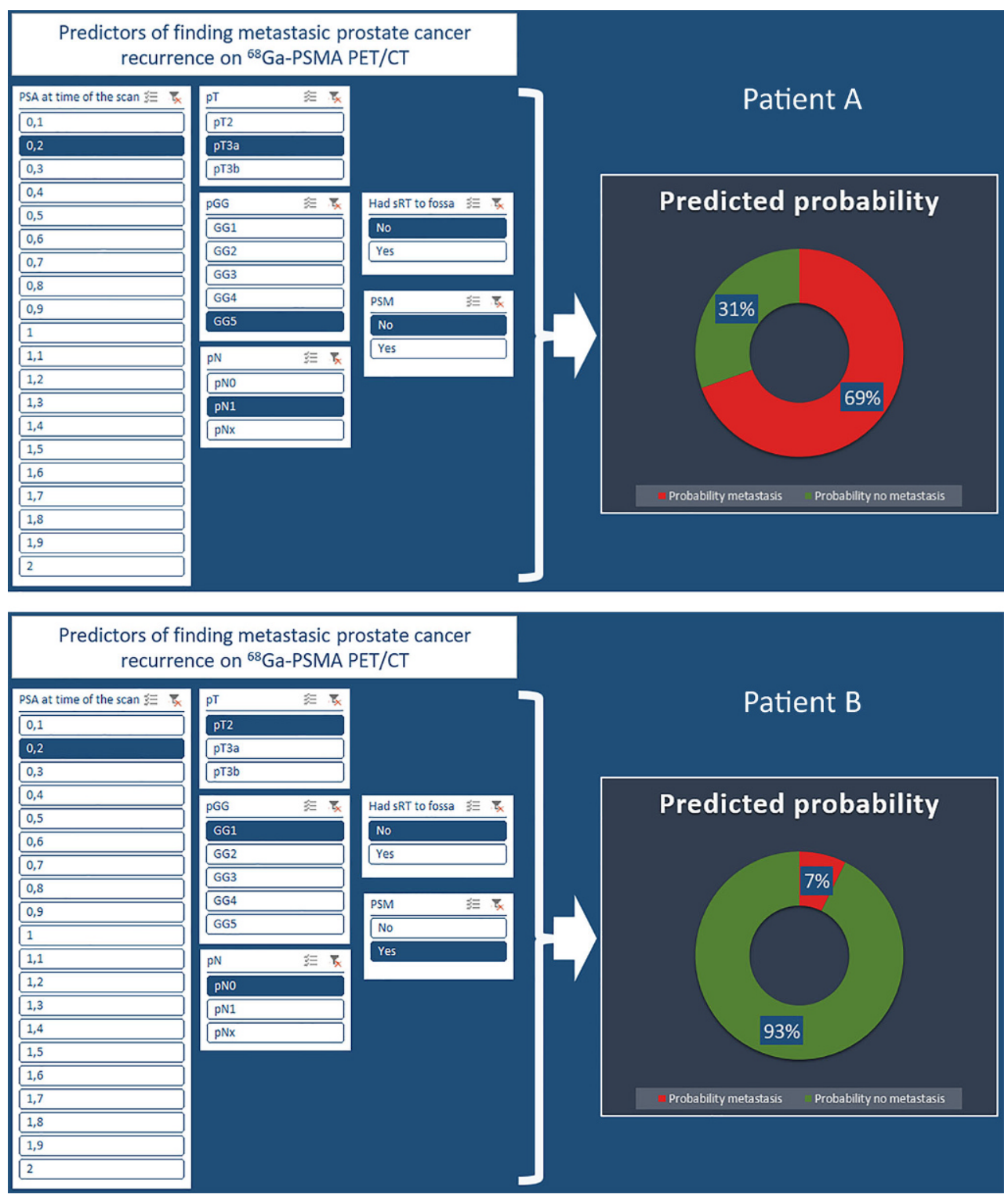

beïnvloeden [6, 7]. De detectie van prostaatkankerrecidief buiten de prostaatfossa beïnvloedt de planning van nabestraling op de prostaatfossa en maakt metastasegerichte therapie mogelijk. Uit onze resultaten blijkt dat, naast de PSA-waarde ten tijde van de PSMA PET/CT-scan, ook de radicale prostatectomievariabelen $\mathrm{pGG}$, snijrandstadium en $\mathrm{pN}$-stadium significante voorspellers zijn voor het vinden van prostaatkankerrecidief buiten de prostaatfossa met behulp van de PSMA PET/CT-scan. Al deze variabelen dienen in overweging te worden genomen voor het bepalen van het juiste moment om de PSMA PET/CTscan te verrichten. Ter illustratie, een patiënt met een pT3aGG5pN0R0-prostaatcarcinoom bij wie overwogen wordt de prostaatfossa na te bestralen, heeft bij een PSA-waarde van $0,2 \mathrm{ng} / \mathrm{ml}$ een kans van $51 \%$ om gediagnosticeerd te worden met een prostaatkankerrecidief buiten de prostaatfossa op de PSMA PET/CTscan. Deze kans is slechts $7 \%$ voor een patiënt met een pT2GG1pN0R1-tumor bij dezelfde PSA-waarde. Er werden geen klinische variabelen gevonden die onderscheidend waren bij een recidief in de lokale klieren of een recidief op afstand. Om de locatie van het recidief te bepalen, blijft het noodzakelijk een PSMA PET/CT-scan te verrichten.

In de richtlijnen van de NVU en de EAU wordt niet duidelijk beschreven of een PSMA PET/CT-scan beter bij een PSA-waarde van bijvoorbeeld 0,2, 0,4 of $1,0 \mathrm{ng} / \mathrm{ml}$ gemaakt kan worden. Onze resultaten laten zien dat het effect van wachten op een hogere PSAwaarde en de daarmee samengaande detectierate door de PSMA PET/CT-scan beïnvloed wordt door verschillende tumorkarakteristieken. Om dit effect inzichtelijk te maken, hebben we de resultaten verwerkt tot een model (https://psma.prostatecancerriskcalculator.com/).

We willen benadrukken dat het gepresenteerde dashboard niet bedoeld is om het startmoment 
Tabel 3 Het aantal scans dat is voorkomen en het aantal scans dat uitzaaiingen niet heeft gedetecteerd bij gebruik van het model bij verschillende afkapwaarden

\begin{tabular}{|c|c|c|c|c|c|c|}
\hline \multirow[b]{2}{*}{ afkapwaarde } & \multicolumn{2}{|c|}{$\begin{array}{l}\text { geen uitzaaiingen } \\
\text { met PSMA PET/CT }\end{array}$} & \multicolumn{2}{|c|}{$\begin{array}{l}\text { wel uitzaaiingen } \\
\text { met PSMA PET/CT }\end{array}$} & \multirow[t]{2}{*}{$\begin{array}{l}\text { PSMA PET/CT-scan } \\
\text { voorkomen (\%) }\end{array}$} & \multirow[t]{2}{*}{$\begin{array}{l}\text { uitzaaiingen gemist } \\
\text { met PSMA PET/CT (\%) }\end{array}$} \\
\hline & $<$ afkapwaarde & $\geq$ afkapwaarde & $<$ afkapwaarde & $\geq$ afkapwaarde & & \\
\hline $16 \%$ & 30 & 215 & 5 & 169 & 8,4 & 2,9 \\
\hline $20 \%$ & 58 & 187 & 9 & 165 & 16 & 5,2 \\
\hline $25 \%$ & 81 & 164 & 22 & 152 & 25 & 13 \\
\hline $30 \%$ & 110 & 135 & 29 & 145 & 33 & 17 \\
\hline $40 \%$ & 172 & 73 & 51 & 123 & 53 & 29 \\
\hline
\end{tabular}

van een vervolgbehandeling te bepalen. De PSMA PET/CT-scan heeft een betere detectierate bij een hogere PSA-waarde. Echter, indien er besloten is de prostaatfossa na te bestralen, moet dit zo snel mogelijk gebeuren [6]. In het PSMA-tijdperk moet de winst van betere detectie bij een hogere PSA-waarde afgewogen worden tegen een mogelijk slechtere uitkomst van de salvagebehandeling bij een hogere PSA-waarde. De oncologische uitkomst van salvagebehandelingen in het PSMA PET/CT-tijdperk moet onderzocht worden in prospectieve trials, voordat definitief gezegd kan worden wat het beste moment is van scannen en behandelen. Onze resultaten kunnen de winst van afwachten helpen inschatten. Modellen waarbij ultrasensitieve PSA-metingen gebruikt worden, kunnen het PSA-verloop en dus juiste moment van behandelen helpen bepalen [10].

Als nabestraling op de prostaatfossa overwogen wordt, kan het dashboard gebruikt worden om te kijken of de kans dat de PSMA PET/CT-scan invloed heeft op het beleid, een reële kans is. Ons advies is om een minimale afkapwaarde van $20 \%$ op het gepresenteerde dashboard aan te houden voordat er een PSMA PET/CT-scan gemaakt wordt. Dit advies is gebaseerd op de verhouding tussen de onnodige negatieve PSMA PET/CT-scans en de PSMA PET/CTscans die wel een prostaatkankerrecidief buiten de prostaatfossa detecteerden onder deze waarde. Bij de voorgestelde afkapwaarde van $20 \%$ heeft één op de vijf PSMA PET/CT-scans invloed op het vervolgbeleid. In de literatuur wordt een impact van $29-30 \%$ genoemd [11, 12]. Onze resultaten laten zien dat dit getal beïnvloed wordt door de patiëntkarakteristieken van het beschreven cohort. Uiteraard is het zo dat de klinische indicatie om de PSMA PET/CT-scan te maken de gebruikte afkapwaarde kan beïnvloeden. Zoals hiervoor beschreven, de EAU-richtlijn adviseert om, zodra besloten is na te bestralen op het prostaatbed, deze bestraling zo snel mogelijk te doen [6]. Echter, bij patiënten met een biochemisch recidief na radicale prostatectomie kan surveillance met mogelijk uitgestelde nabestraling worden overwogen indien de PSA-verdubbeltijd groter is dan één jaar en de pGG < 4 [13].

De PSMA PET/CT kan patiënten categoriseren in een groep die goed reageert op nabestraling (nega- tieve PSMA PET/CT of lokaal recidief) en een groep die slecht reageert op nabestraling (prostaatkankerrecidief buiten de prostaatfossa op de PSMA PET/CT) [14]. PSMA PET/CT maakt het daarmee mogelijk een groep te identificeren die in aanmerking kan komen voor nabestraling op de prostaatfossa. Onze resultaten laten zien dat er vier klinische variabelen voorspellend zijn voor het detecteren van prostaatkankerrecidief buiten de prostaatfossa met PSMA PET/CT; PSA ten tijde van de PSMA PET/CT-scan, pGG, snijrandstadium en $\mathrm{pN}$-stadium.

De associatie tussen de PSA-waarde ten tijde van de PSMA PET/CT en de kans op een positieve PSMA $\mathrm{PET} / \mathrm{CT}$-scan is reeds aangetoond in de literatuur [15]. De associatie tussen pGG en de kans op het vinden van prostaatkankerrecidief buiten de prostaatfossa komt overeen met preklinisch onderzoek waarin aangetoond werd dat de expressie van de PSMA-receptor toeneemt bij hogere pGG [16, 17]. Ook wordt er een hogere PSMA-11-uptake gezien in tumoren met een hoger gradestadium in de primaire setting [18]. Onze resultaten zijn echter tegenstrijdig met de resultaten uit meerdere andere studies, die deze relatie niet vinden [11, 15, 19, 20]. Een mogelijke verklaring hiervoor is dat deze onderzoeken kleinere cohorten beschrijven en patiënten includeerde die hormoontherapie ontvingen vóór de PSMA PET/CT. Het gebruik van hormoontherapie heeft namelijk invloed op de PSMAexpressie [14]. Een positieve snijrand vergroot de kans op het hebben van een lokaal recidief [4]. In onze resultaten is dit waar te nemen, want patiënten met een positieve snijrand hebben een kleinere kans op een prostaatkankerrecidief buiten de prostaatfossa op de PSMA PET/CT-scan. Ten slotte, patiënten met een tumor met bewezen metastasen ( $\mathrm{pN} 1)$ hebben een hoger risico om gedetecteerd te worden met een metastase op de PSMA PET/CT-scan. Onze resultaten toonden geen klinische variabelen die konden differentiëren tussen patiënten met metastasen binnen of buiten de bekkenregio. Het blijft daarom nodig om een PSMA PET/CT-scan te maken om te kunnen onderscheiden tussen patiënten met een locoregionaal prostaatkankerrecidief of een prostaatkankerrecidief buiten het bekken.

In het cohort in onze studie had ongeveer $50 \%$ van alle patiënten een negatieve PSMA PET/CT-scan. 
Tabel 4 De odds ratio's van verschillende klinische variabelen die differentiëren tussen de kans op het vinden van uitzaaiingen in het bekken of op afstand versus geen metastasen

\begin{tabular}{|c|c|c|c|c|c|}
\hline variabele & $\begin{array}{l}\text { uitzaaiingen op } \\
\text { afstand (ref) }\end{array}$ & geen uitzaaiingen & $p$-waarde & $\begin{array}{l}\text { alleen uitzaaiingen in pelviene } \\
\text { lymfeklieren }\end{array}$ & $p$-waarde \\
\hline intercept & & $1,74(0,50-2,99)$ & 0,006 & $0,74(-0,63-2,11)$ & 0,29 \\
\hline $\log _{2} a^{a}$ & & $-0,82(-1,20-0,45)$ & $<0,001$ & $-0,18(-0,56-0,20)$ & 0,4 \\
\hline \multicolumn{6}{|l|}{ pGG } \\
\hline $\mathrm{pGG1}$ & ref & & & & \\
\hline pGG2 & & $-0,16(-1,36-1,04)$ & 0,8 & $0,34(-1,00-1,68)$ & 0,6 \\
\hline pGG3 & & $-0,64(-1,89-0,61)$ & 0,3 & $0,45(-0,92-1,83)$ & 0,5 \\
\hline pGG4 & & $-0,73(-2,07-0,61)$ & 0,3 & $-0,01(-1,49-1,46)$ & $>0,9$ \\
\hline pGG5 & & $-1,93(-3,35-0,51)$ & 0,008 & $0,25(-1,23-1,73)$ & 0,7 \\
\hline \multicolumn{6}{|c|}{ pT-stadium } \\
\hline pT2 & ref & & & & \\
\hline рT3a & & $-0,68(-1,51-0,15)$ & 0,11 & $-0,61(-1,49-0,28)$ & 0,18 \\
\hline рТ3b & & $0,01(-0,88-0,91)$ & $>0,9$ & $0,13(-0,80-1,06)$ & 0,8 \\
\hline \multicolumn{6}{|c|}{ pN-stadium } \\
\hline pNO & ref & & & & \\
\hline $\mathrm{pNx}$ & & $-0,57(-1,38-0,24)$ & 0,17 & $-0,05(-0,91-0,82)$ & 0,9 \\
\hline pN1 & & $-0,98(-1,82-0,15)$ & 0,020 & $-0,15(-0,98-0,68)$ & 0,7 \\
\hline \multicolumn{6}{|c|}{ positief snijvlak } \\
\hline nee & ref & & & & \\
\hline ja & & $0,36(-0,30-1,02)$ & 0,3 & $-0,33(-1,02-0,36)$ & 0,3 \\
\hline \multicolumn{6}{|c|}{ nabestraling op het prostaatbed } \\
\hline nee & ref & & & & \\
\hline ja & & $-0,50(-1,21-0,22)$ & 0,17 & $-0,25(-0,99-0,49)$ & 0,5 \\
\hline
\end{tabular}

Prostaatkankerrecidief kan om verschillende redenen gemist worden met PSMA PET/CT. Ten eerste, bij prostaatkanker ontbreekt expressie van PSMA in 0-9\% van de tumoren $[21,22]$. Ten tweede, de uitgescheiden tracer in de blaas kan lokale recidieven overstralen. Het lage aantal lokale recidieven in ons cohort doet dit inderdaad vermoeden [23]. Ten derde, PSMA PET/CT mist kleine lymfekliermetastasen door de spatiële resolutie van ${ }^{68}$ Gallium $[24,25]$.

Het gepresenteerde model kan gebruikt worden om onnodige negatieve PSMA PET/CT-scans te voorkomen. De kosten van een PSMA PET/CT-scan liggen in Nederland rond de $€ 400$ tot $€ 1.000$. Bij patiënten die in aanmerking komen voor nabestraling op de prostaatfossa kan het model gebruikt worden om vooraf te bepalen bij welke PSA-waarde PSMA PET/CT ingezet zal worden en wat het daaropvolgend beleid is. Bij patiënten die in aanmerking komen voor een metastasegerichte therapie geeft het model meer inzicht in wanneer er een reële kans is op het detecteren van een metastase. Dit kan meerdere opeenvolgende negatieve PSMA PET/CT-scans voorkomen. De kosten van het nabestralen van de prostaatfossa liggen rond de $€ 10.000,-$. Indien bij het gebruik van het model de afkapwaarde van $20 \%$ gebruikt wordt, zal bij één op de vijf patiënten niet-succesvolle nabestraling voorkomen worden. Daarmee is PSMA PET/CT kosteneffectief. Echter, de kosten van verdere metastasegerichte behandelingen en of uitbreiding van het bestralingsveld zijn hierbij niet meegenomen. Prospectieve studies die ook de effectiviteit van op PSMA gerichte behandelingen onderzoeken, zijn nodig om verdere kosteneffectiviteit te bepalen.

De hier beschreven studie is niet zonder beperkingen. Ten eerste, het is een retrospectieve studie. De keuze om een PSMA PET/CT-scan te maken, was in handen van de uroloog, wat om die reden zou kunnen leiden tot een selectiebias. Ten tweede, positieve laesies op de PSMA PET/CT-scan zijn niet histopathologisch gevalideerd. In de huidige praktijk worden, door de hoge positief-voorspellende waarde van PSMA PET/CT, laesies op de PSMA PET/CT-scan vaak niet histologisch gevalideerd [25-28]. Ten derde, de meeste patiënten hadden maar één of twee meetbare PSA-waarden voordat de PSMA PET/CT-scan gemaakt werd. Dit maakte het onmogelijk de PSA-verdubbelingstijd te berekenen en op te nemen als variabele in ons model. Ten slotte, voordat een model gebruikt kan worden in de dagelijkse praktijk is externe validatie gewenst. Echter, we hebben statistisch overfitten van de data geminimaliseerd om de generaliseerbaarheid van dit model te verbeteren.

Het gebruik van fluor-gelabelde PSMA-tracers, zoals ${ }^{18} \mathrm{~F}$-DCFPyL en ${ }^{18} \mathrm{~F}$-PSMA-1007, heeft verschillende voordelen boven gallium-gelabelde tracers. Zo is met fluortracers een hogere resolutie mogelijk en is het produceren en distribueren van fluortracers gemakkelijker door de langere halfwaardetijd [29]. Er is een 
duidelijke toename van fluortracers in Nederland ten opzichte van gallium-tracers. Het gepresenteerde model is gebaseerd op de gallium-PSMA PET/CT-scan. Voordat dit model toegepast kan worden bij fluor-tracers, dient er een externe validatie verricht te worden. Maar omdat beide tracers aangrijpen op dezelfde PSMA-receptor is de verwachting dat dezelfde klinische variabelen invloed zullen hebben op de detectierate. Het is mogelijk dat de hogere spatiële resolutie en de verminderde urine-excretie invloed hebben op de detectie van lokale recidieven en kleine lymfeklieren [29].

Dit is het grootste beschreven patiëntencohort met een biochemisch recidief (PSA $<2,0 \mathrm{ng} / \mathrm{ml}$ ) na radicale prostatectomie, waarbij patiënten die hormoontherapie ontvingen na de radicale prostatectomie maar voor de PSMA PET/CT-scan geëxcludeerd werden. Het gebruik van hormonen beïnvloedt de expressie van PSMA in prostaatkankercellen [30]. Bij patiënten met hormoongevoelig prostaatkanker leidt de initiatie van hormonale therapie tot een afname van de sensitiviteit van PSMA PET/CT. Bij patiënten met castratieresistent prostaatkanker leidt de initiatie van additionele hormonale therapie juist tot een toename van de sensitiviteit van de PSMA PET/CT [31]. Indien na radicale prostatectomie onder hormonale therapie sprake is van een meetbaar PSA, is PSMA PET/CT zeer sensitief voor het detecteren van het prostaatkankerrecidief en is gebruik van dit dashboard niet zinvol [20].

Een eerder gepubliceerd model voorspelt de kans op het hebben van een positieve PSMA PET/CT-scan [20]. Echter, in deze studie werden ook patiënten die hormonale therapie kregen geïncludeerd. Zoals eerder beschreven heeft hormonale therapie invloed op de relatie tussen voorspellers als pGG en de kans op het detecteren van prostaatkanker met PSMA PET/CT. Daarnaast vinden wij dat PSMA PET/CT gebruikt moet worden om metastasen uit te sluiten of aan te tonen, niet om lokale recidieven aan te tonen. Als het aantonen van een lokaal recidief het doel is van het onderzoek, dan is PET/MRI beter geschikt dan PET/CT [23]. De uiteindelijke meerwaarde van PSMA PET/CT moet zich bewijzen in verbeterde oncologische uitkomsten van salvagebehandelingen in het PSMA PET/CT-tijdperk. Dit vereist goed opgezette prospectieve studies. Daarnaast moeten toekomstige studies zich richten op het verbeteren van de sensitiviteit van de PSMA PET/CT-scan.

\section{Conclusie}

Bij patiënten met een biochemisch recidief na radicale prostatectomie zijn de PSA-waarde ten tijde van de PSMA PET/CT-scan en de radicale prostatectomievariabelen pGG, snijrandstadium en pN-stadium voorspellend voor het detecteren van prostaatkankerrecidief buiten de prostaatfossa op de PSMA PET/CT-scan. Onze resultaten laten zien dat de PSA- waarde ten tijde van de PSMA PET/CT-scan niet de enige leidraad moet zijn om het juiste moment van scannen te bepalen. Het dashboard (https:// psma.prostatecancer-riskcalculator.com/) kan gebruikt worden om het optimale moment van scannen te bepalen, maar externe validatie is essentieel. Prospectieve studies zijn nodig om de effectiviteit van PSMA-gerichte salvagebehandelingen te bepalen.

Open Access This article is distributed under the terms of the Creative Commons Attribution 4.0 International License (http://creativecommons.org/licenses/by/4.0/), which permits unrestricted use, distribution, and reproduction in any medium, provided you give appropriate credit to the original author(s) and the source, provide a link to the Creative Commons license, and indicate if changes were made.

\section{Literatuur}

1. Bill-Axelson A, Holmberg L, Garmo H, Taari K, Busch C, Nordling S, et al. Radical prostatectomy or watchful waiting in prostate cancer-29-year follow-up. N Engl J Med. 2018;379(24):2319-29.

2. Han M, Partin AW, Pound CR, Epstein JI, Walsh PC. Longterm biochemical disease-free and cancer-specific survival following anatomic radical retropubic prostatectomy. The 15-year Johns Hopkins experience. Urol Clin North Am. 2001;28(3):555-65.

3. Bolla M, Poppel H van, Tombal B, Vekemans K, Da Pozzo L, Reijke TM de, et al. Postoperative radiotherapy after radical prostatectomy for high-risk prostate cancer: long-term results of a randomised controlled trial (EORTC trial 22911). Lancet. 2012;380(9858):2018-27.

4. Tendulkar RD, Agrawal S, Gao T, Efstathiou JA, Pisansky TM, MichalskiJM, etal. Contemporaryupdate of a multi-institutional predictive nomogram for salvage radiotherapy after radical prostatectomy. JClin Oncol. 2016;34(30):3648-54.

5. Gandaglia G, Briganti A, Clarke N, Karnes RJ, Graefen M, Ost $\mathrm{P}$, et al. Adjuvant and salvage radiotherapy after radical prostatectomy in prostate cancer patients. Eur Urol. 2017;72(5):689-709.

6. EAU. EAU Guidelines. Edition presented at the EAU Annual Congress Barcelona 2019. Arnhem: EAU Guidelines Office; 2019.

7. Reijke TM de, Coenen JLLM, Giessen R van der, Gietema JA, Janssen MJR, et al. Module PSMA PET/ CT voor de richtlijn Prostaatcarcinoom. Utrecht: Nederlandse Vereniging voor Urologie; 2019.

8. VanCalster B, NieboerD, VergouweY,CockB de, PencinaMJ, Steyerberg EW. A calibration hierarchy for risk models was defined: from utopia to empirical data. J Clin Epidemiol. 2016;74:167-76.

9. Steyerberg EW. Clinical prediction models a practical approach to development, validation, and updating. New York: Springer; 2009.

10. Grivas N, Bruin D de, Barwari K, Muilekom E van, Tillier C, Leeuwen PJ van, et al. Ultrasensitive prostate-specific antigen level as a predictor of biochemical progression after robot-assisted radical prostatectomy: towards riskadapted follow-up. JClin Lab Anal. 2019;33(2):e22693.

11. BoretaL, GadzinskiAJ, WuSY,Xu M, GreeneK, QuanstromK, et al. Location of recurrence by Gallium-68 PSMA-11 PET scan in prostate cancer patients eligible for salvage radiotherapy. Urology. 2019;129:165-71.

12. Leeuwen PJ van, Stricker P, Hruby G, Kneebone A, Ting F, Thompson B, et al. (68) Ga-PSMA has a high detection rate 
of prostate cancer recurrence outside the prostatic fossa in patients being considered for salvage radiation treatment. BJU Int. 2016;117(5):732-9.

13. Broeck T van den, Bergh RCN van den, Briers E, Cornford $P$, Cumberbatch M, Tilki D, et al. Biochemical recurrence in prostate cancer: the European Association of Urology prostate cancer guidelines panel recommendations. Eur UrolFocus. 2020;6(2):231-4.

14. Emmett L, Leeuwen PJ van, Nandurkar R, Scheltema MJ, Cusick T, Hruby G, et al. Treatment outcomes from (68)Ga-PSMA PET/CT-informed salvage radiation treatment in men with rising psa after radical prostatectomy: prognostic value of a negative PSMA PET. J Nucl Med. 2017;58(12):1972-6.

15. Perera M, Papa N, Roberts M, Williams M, Udovicich C, Vela I, et al. Gallium-68 Prostate-specific membrane antigen positron emission tomography in advanced prostate cancer-updated diagnostic utility, sensitivity, specificity, and distribution of prostate-specific membrane antigenavid lesions: a systematic review and meta-analysis. Eur Urol. 2020;77(4):403-17.

16. Marchal C, Redondo M, Padilla M, Caballero J, Rodrigo I, Garcia J, et al. Expression of prostate specific membrane antigen (PSMA) in prostatic adenocarcinoma and prostatic intraepithelial neoplasia. Histol Histopathol. 2004;19(3):715-8.

17. Kasperzyk JL, Finn SP, Flavin R, Fiorentino M, Lis R, Hendrickson WK, et al. Prostate-specific membrane antigen protein expression in tumor tissue and risk of lethal prostate cancer. Cancer Epidemiol Biomarkers Prev. 2013;22(12):2354-63.

18. Uprimny C, Kroiss AS, Decristoforo C, Fritz J, Guggenberg E von, Kendler D, et al. (68)Ga-PSMA-11 PET/CT in primary staging of prostate cancer: PSA and Gleason score predict the intensity of tracer accumulation in the primary tumour. Eur J Nucl Med Mol Imaging. 2017;44(6):941-9.

19. Afshar-Oromieh A, Holland-Letz T, Giesel FL, Kratochwil C, Mier W, Haufe S, et al. Diagnostic performance of (68)GaPSMA-11 (HBED-CC) PET/CT in patients with recurrent prostate cancer: evaluation in 1007 patients. Eur J Nucl Med Mol Imaging. 2017;44(8):1258-68.

20. Rauscher I, Duwel C, Haller B, Rischpler C, Heck MM, Gschwend JE, et al. Efficacy, Predictive factors, and prediction nomograms for (68)Ga-labeled prostate-specific membrane antigen-ligand positron-emission tomography/computed tomography in early biochemical recurrent prostate cancer after radical prostatectomy. Eur Urol. 2018;73(5):656-61.

21. ChakrabortyPS, Tripathi M,Agarwal KK, KumarR, VijayMK, Bal C. Metastatic poorly differentiated prostatic carcinoma with neuroendocrine differentiation: negative on $68 \mathrm{Ga}-$ PSMAPET/CT. Clin Nucl Med. 2015;40(2):e163-6.

22. Zacho HD, Nielsen JB, Haberkorn U, Stenholt L, Petersen LJ. Ga-PSMA PET/CT for the detection of bone metastases in prostate cancer: a systematic review of the published literature. Clin Physiol Funct Imaging. 2017; https://doi. org/10.1111/cpf.12480.

23. Freitag MT, Radtke JP, Afshar-Oromieh A, Roethke MC, Hadaschik BA, Gleave M, et al. Local recurrence of prostate cancer after radical prostatectomy is at risk to be missed in
(68)Ga-PSMA-11-PET of PET/CT and PET/MRI: comparison with mpMRI integrated in simultaneous PET/MRI. Eur J Nucl Med Mol Imaging. 2017;44(5):776-87.

24. Leeuwen PJ van, Emmett L, Ho B, Delprado W, Ting F, Nguyen Q, et al. Prospective evaluation of 68Galliumprostate-specific membrane antigen positron emission tomography/computed tomography for preoperative lymph node staging in prostate cancer. BJU Int. 2017;119(2):209-15.

25. Budaus L, Leyh-Bannurah SR, Salomon G, Michl U, Heinzer $\mathrm{H}$, Huland $\mathrm{H}$, et al. Initial experience of (68)Ga-PSMA $\mathrm{PET} / \mathrm{CT}$ imaging in high-risk prostate cancer patients prior to radical prostatectomy. Eur Urol. 2016;69(3):393-6.

26. Maurer T, Gschwend JE, Rauscher I, Souvatzoglou M, Haller B, Weirich G, et al. Diagnostic efficacy of (68)galliumPSMA positron emission tomography compared to conventional imaging for lymph node staging of 130 consecutive patients with intermediate to high risk prostate cancer+. JUrol. 2016;195(5):1436-43.

27. Thalgott M, Duwel C, Rauscher I, Heck MM, Haller B, Gafita A, et al. One-stop-shop whole-body (68)Ga-PSMA-11 $\mathrm{PET} / \mathrm{MRI}$ compared with clinical nomograms for preoperative tand $\mathrm{n}$ staging of high-risk prostate cancer. J Nucl Med. 2018;59(12):1850-6.

28. Leeuwen PJ van, Donswijk M, Nandurkar R, Stricker P, Ho B, HeijminkS, et al. 68Ga PSMAPET/CT predicts complete biochemical response from radical prostatectomy and lymph node dissection in intermediate and high-risk prostate cancer. BJU Int. 2019;124(1):62-8.

29. RoweSP, Gorin MA, AllafME, Pienta KJ, Tran PT, PomperMG, et al. PET imaging of prostate-specific membrane antigen in prostate cancer: current state of the art and future challenges. Prostate Cancer Prostatic Dis. 2016;19(3):223-30.

30. Hope TA, Truillet C, Ehman EC, Afshar-Oromieh A, Aggarwal R, Ryan CJ, et al. 68Ga-PSMA-11 PET imaging of response to androgen receptor inhibition: first human experience. J Nucl Med. 2017;58(1):81-4.

31. Emmett LM, Yin C, Crumbaker M, Hruby G, Kneebone A, Epstein R, et al. Rapid modulation of PSMA expression by androgen deprivation: serial (68)Ga PSMA-11 PET in men with hormone sensitive and castrate resistant prostate cancer commencing androgen blockade. J Nucl Med. 2019;60(7):950-4.

drs. Henk B. Luiting, arts-onderzoeker, promovendus

dr. Pim J. van Leeuwen, uroloog

drs. Sebastiaan Remmers, statisticus, promovendus

drs. Maarten Donswijk, nucleair geneeskundige

drs. Martijn B. Busstra, uroloog

drs. Ingrid L. Bakker, arts-assistent urologie

dr. Tessa Brabander, nucleair geneeskundige

dr. Marcel Stokkel, nucleair geneeskundige

dr. Henk G. van der Poel, uroloog

prof. dr. Monique J. Roobol, epidemioloog 